\title{
AMH as the primary marker for fertility
}

\section{Didier Dewailly ${ }^{1,2}$ and Joop Laven ${ }^{3}$}

${ }^{1}$ INSERM, Laboratory of Development and Plasticity of the Neuroendocrine Brain, Jean-Pierre Aubert Research Centre, U1172, Lille, France, ${ }^{2}$ Université de Lille, Faculté de Médecine, Lille, France, and ${ }^{3}$ Division of Reproductive Endocrinology and Infertility, Department of Obstetrics and Gynaecology, Erasmus University Medical Center, Rotterdam, The Netherlands
Correspondence should be addressed to $\mathrm{D}$ Dewailly

Email

didier.dewailly@orange.fr

\begin{abstract}
In women, the anti-Müllerian hormone (AMH) is secreted by the granulosa cells of growing follicles. Its measurement is strongly correlated with antral follicle count and represents a reliable marker of ovarian reserve. It also has the advantage of being highly reproducible since it has little variation within and between cycles. However, although it seems to be a good quantitative reflection of the ovarian reserve, it does not assess oocyte or embryo quality. This drawback precludes any good prediction of female fertility in the general population as well as in specific subgroups of patients. However, the AMH assay can become an indirect marker of the remaining female fertile years in some cases such as in those women who are at risk for premature ovarian failure or in those suffering from polycystic ovary syndrome. Its interest is no more to be proven in assisted reproductive technology where it is a valuable aid to the choice of the proposed techniques, ovarian stimulation protocols and gonadotropin dosage. AMH is finally very informative in monitoring cancer patients having received gonadotoxic drugs or having undergone mutilating ovarian surgeries. In conclusion, although it cannot be considered as a reliable predictor of pregnancy in women, AMH is now a useful tool in the management and treatment of female infertility.
\end{abstract}

\section{Introduction}

In recent years, the serum anti-Müllerian hormone $(\mathrm{AMH})$ assay has taken an increasingly important place in the management of female fertility. But what is its real reliability and usefulness in predicting fertility? The purpose of this review is to distinguish between irrational fantasies and baseless pessimism.

First a little physiology. AMH is produced by follicle granulosa cells as soon as they begin to grow and is expressed throughout folliculogenesis. By immunohistochemistry of ovarian tissue of normal women, the absence of AMH secretion by the primordial follicles was shown, whereas it was largely expressed in primary, secondary, pre-antral follicles and early antral follicles. Its expression then decreases from the dominant follicle stage (1). In vivo, in women, it has been shown that $60 \%$ of the circulating AMH comes from follicles with size between 5 and $8 \mathrm{~mm}$ (2) whereas, on the other hand, follicles larger than $10 \mathrm{~mm}$ do not express (c) 2019 European Society of Endocrinology Printed in Great Britain practically more. Inhibition of the AMH gene in mice (AMHKO) clarified its specific role in folliculogenesis (3, $4)$. The results suggest that AMH exerts an inhibitory action on initial follicular recruitment, thus avoiding premature depletion of the primordial follicle pool (5, 6). In addition, in AMHKO mice, a lower FSH level was found suggesting an increased sensitivity of follicles to FSH in the absence of AMH (6). Thus, AMH has an inhibitory role on the cyclical recruitment of growing follicles by inhibition of their follicular response to FSH $(6,7,8)$. AMH can act as a 'follicular doormat' and ensure that each small antral follicle produces the minimum of estradiol prior to selection (i.e., up to a follicular diameter of $\sim 8 \mathrm{~mm}$ ). Beyond that step, in the dominant follicle(s), this action fades during the inter-cycle spike of FSH, which allows estradiol to override AMH and induce cell differentiation processes specific to terminal follicular maturation $(2,9,10)$.

Published by Bioscientifica Ltd. 


\section{Section 1: AMH is the primary marker for fertility in some situations (Didier Dewailly)}

These different roles of the AMH explain all the interest that its assay raises in reproductive medicine, but let us eliminate from the outset an idea that is based on a fantasy and on a lack of physiological knowledge: in the general population of women of child-bearing age, AMH is not a predictive marker of pregnancy chances. These depend on innumerable factors other than ovarians. This will be discussed in Section 2. Some studies found a negative association between the serum AMH level and time to pregnancy in fertile women, but large variation in fecundity within similar AMH concentrations precluded any establishment of cut-offs (11).

Let us therefore restrict ourselves to what the serum AMH can predict: the state of the ovarian reserve (OR) and the growing follicle pool. Therefore, its main uses are on the one hand the detection of the anomalies which touch these two ovarian properties that are fundamental for fertility and secondly, their quantitative estimation to guide their therapeutic manipulation in the context of an ART for all indications. The OR of a woman is represented by the stock of primordial follicles. It is defined at birth and will gradually decrease during life, by the growth of several follicles at each cycle and mainly by their atresia. OR is not directly measurable, but the number of growing follicles is strongly correlated with the size of the primordial follicle pool. Therefore, the markers of these follicles are considered good reflections of OR. Thus, the follicles with size $<10 \mathrm{~mm}$ and visible on ultrasound ('antral follicular count', AFC) have been widely used and still are! - in this indication. The AMH assay now competes with AFC since its level is strongly correlated with this parameter and from a theoretical point of view, reflects follicular growth over a wider range $(12,13)$. However, some authors make it clear that using AMH or $\mathrm{AFC}$ as markers of OR is an abuse of language and suggest that these markers are more representative of a woman's 'ovulatory potential' (14).

Thus, the AMH assay can be considered as the primary marker for fertility when OR and/or growing follicle pool are altered, either in excess as in the polycystic ovary syndrome (PCOS), or by default, secondary to early follicular depletion, whether primitive or secondary.

PCOS affects $5-10 \%$ of women of child-bearing age $(15,16)$. Due to the increased number of growing follicles, serum AMH levels in women with PCOS are 2- to 4-fold higher than in normal women $(17,18)$. In addition, in vitro production of AMH by granulosa cells is higher in PCOS patients when they are anovulatory (19). In good agreement, the serum AMH assay provides an assessment of the severity of ovulatory dysfunction and the AMH/AFC ratio is higher in PCOS phenotypes with anovulation (20). These data suggest intrinsic dysregulation of granulosa cells, implicated in PCOS anovulation, in which AMH could play a major role. This suggests that the AMH assay could be used as a predictor of response to ovulation inducers, of which clomiphene citrate (CC) is the firstline therapy. One study suggests that high AMH levels are associated with higher resistance to $\mathrm{CC}$, the need for higher doses and lower pregnancy rates (21). However, these data need confirmation in larger cohorts of patients and with the new automated assays. The results are contradictory for induction of gonadotropin ovulation in patients with PCOS. Indeed, some authors claimed that the higher the level of $\mathrm{AMH}$, the greater the dose of gonadotropin to induce ovulation and the longer stimulation duration $(22,23)$. On the contrary, others did not find a correlation between initial AMH level and gonadotropin sensitivity in anovulatory PCOS patients $(24,25)$. Similarly, the link between serum AMH level and the effectiveness of ovarian drilling is controversial since some consider the $\mathrm{AMH}$ as a good predictor of ovarian response to drilling $(26,27)$, while others prefer other assays such as serum total testosterone (28). The predictive power of $\mathrm{AMH}$, alone, on the ovarian sensitivity to ovulation-inducing treatments, in the PCOS patient, therefore remains very controversial. It therefore seems unreasonable to date to rely on serum AMH level alone to decide whether or not to use a particular ovulation-inducing treatment, and the $\mathrm{AMH}$ value alone does not reflect the efficacy and chances of pregnancy obtained by these treatments. In the management of PCOS, the only real progress to date remains the prediction of the risk of hyperstimulation during an IVF attempt (see below).

The other important cause of abnormality of folliculogenesis is primary ovarian failure (POF). A low serum AMH level is the earliest marker reflecting a quantitative decline in OR (29). But the problem is that there is currently no consensus threshold defining a decline in OR. Many authors agree on a threshold at $1 \mathrm{ng} / \mathrm{mL}$ or $7.14 \mathrm{pmol} / \mathrm{L}$ (30), but this threshold does not predict the chances of pregnancy of a patient since even at undetectable AMH levels, pregnancy may occur, especially in young patients (31). In fact, this threshold here is misused as it has been evaluated in targeted populations, in the context of an ART, with the aim of predicting a poor response (see below) and not the detection 
of a POF. We cannot assimilate a bad response, unsuited to IVF, to a decrease in OR responsible for hypofecundity in spontaneous cycles. Thus, it would be legitimate to differentiate the threshold of OR beyond which the chances of pregnancy in 'natural' cycles are considered acceptable of the threshold of OR considered necessary in ART, the latter being higher. The 'ultra-sensitive' AMH assays will perhaps one day make this distinction. In one study where pregnancy was not the outcome, using the 'pico-AMH' assay, compared to an AMH level of $2.0 \mathrm{ng} / \mathrm{mL}$, the calculated odd ratios for early menopause associated with $\mathrm{AMH}$ levels of $1.5,1.0$ and $0.5 \mathrm{ng} / \mathrm{mL}$ were 2.6, 7.5 and 23, respectively (32). For now, fertility prognosis should not be based on the single AMH assay but also take into account other parameters such as age in the first place and also BMI, smoking, diseases affecting fecundity and male factor infertility (11).

Ultra-sensitive AMH assays will also be useful for assessing the decline in OR in high-risk situations such as those induced by ovarian-toxic treatments or ovarian surgery. In one study where pregnancy was not the outcome, the 'pico-AMH assay' could discriminate between women recovering spontaneous cycle after chemotherapy and women remaining amenorrheic, while the conventional assay could not (33). However, as far as the prognosis for fertility is concerned, the interpretation of a low AMH level should be conservative. Indeed, the only way to give a predictive value to $\mathrm{AMH}$ for fertility prognosis in these women would be to monitor their long-term reproduction, but such studies are lacking so far.

Ultimately, as discussed below, serum AMH level has only a very weak predictive power of clinical pregnancy in ART but remains very useful for assessing the ovarian response to stimulation and to better adapt treatments.

\section{Section 2: AMH is not the primary marker for fertility (Joop Laven)}

Women are born with a limited number of primordial follicles generally referred to as the primordial follicle pool. Moreover, there are discernible differences between women regarding the number of primordial follicles in that pool. After the age of 30, female fertility starts to decline because a decrease in the number of primordial follicles causing a decrease in the so-called OR. Because the rate at which the OR declines also varies considerably between individual women, the time of exhaustion of the primordial follicle pool, generally referred to as menopause, also differs. Menopause is generally preceded by a period of several years of infertility. The OR refers to both the quantity and quality of the primordial follicle pool (34). Hence, quantity and quality go hand in hand during aging because women accumulate damage in their germ cell line the longer they are exposed to damaging agents. Quality is therefore dependent on the amount of DNA damage and the capacity to repair that damage. Indeed, most genetic variants determining the age of menopause are involved in DNA damage repair and DNA maintenance. Consequently, aging of the germ cell line as a result of inefficient DNA repair appears also to be responsible for failure to reproduce and the subsequent occurrence of menopause. It is therefore conceivable that quality of oocytes is regulated by other factors than those that regulate the numbers of primordial follicles (35).

In a fairly large study looking at fecundity rates in a normal population, the authors showed that women with a low serum AMH level achieved similar pregnancy rates compared to those with normal or high AMH levels. They concluded that neither low nor high AMH levels relative to normal AMH were associated with fecundity in unassisted conceptions in a cohort of fertile women with a history of one or two prior losses (36). A similar study compared fecundity rates between five different quintiles. Compared to women with a medium $\mathrm{AMH}$ (AMH quintiles 2-4) levels, fecundability did not differ significantly in women with lowest $\mathrm{AMH}$ quintile level. In contrast, women with highest $\mathrm{AMH}$ quintile levels had a reduced fecundability even after adjustment for covariates such as the woman's age, BMI, smoking, diseases affecting fecundability and male factor infertility. Irregular menstrual cycles were more prevalent in women with high AMH compared with women with low or medium AMH levels. After exclusion of women with irregular cycles, women with high $\mathrm{AMH}$ still had reduced fecundability rates (37). A third recent study among women aged 30-44 years without a history of infertility who had been trying to conceive for 3 months or less, biomarkers indicating diminished OR compared with normal OR were not associated with reduced fertility. These findings do not support the use of tests determining AMH serum concentrations to assess natural fertility for women with diminished OR (38).

Most studies have addressed the predictive value of AMH during assisted reproductive technology treatments. A meta-analysis selected 47 studies out of 361 nonduplicate studies. Only 17 studies met the eligibility criteria and 13 had extractable data and thus were included in the meta-analysis. That meta-analysis concluded that although serum AMH concentrations, independently of 
Table 1 AMH as the primary marker for fertility.

Cons
AMH correctly predicts the number of follicles or
oocytes after whatever treatment is initiated but it
cannot predict the amount of genetic damage that
eventually determines embryo quality and
subsequent pregnancy.
In normal populations, women with a low serum AMH
level achieve similar pregnancy rates compared to
those with normal or high AMH levels.
There is no direct evidence demonstrating that a lower
AMH is predictive of reduced chance to conceive
naturally after cancer treatment.

\section{Pros}

The AMH assay now competes with antral follicle count since its level is strongly correlated with this parameter and from a theoretical point of view, reflects follicular growth over a wider range.

Some studies found a negative association between the serum AMH level and time to pregnancy in fertile women but large variation in fecundity within similar AMH concentrations precluded any establishment of cut-offs.

The AMH assay can be considered as the primary marker for fertility when primordial follicles and/or growing follicle pool(s) are altered, either in excess as in the polycystic ovary syndrome (PCOS), or by default, secondary to early follicular depletion, whether primitive or secondary, in premature ovarian failure (POF). age, had some association with predicting live birth after assisted conception and could be helpful when counseling couples before undergoing fertility treatment. However, the predictive accuracy and power of $\mathrm{AMH}$ predicting pregnancy was poor (39). A study trying to develop a prediction model for AMH predicting pregnancy outcome reported similar findings. Although three different models demonstrated increasingly poor outcomes with advancing age, lower AMH serum concentrations, even above age 43, were still associated with unexpectedly good pregnancy and delivery outcomes. Moreover these authors also reported that excessively high serum AMH levels were associated with spiking miscarriage rates (40).

Since quality and quantity seem to go hand in hand during normal aging it is conceivable that $\mathrm{AMH}$ might be a good predictor for embryo quality. Several studies have been studying embryo quality in relation to $\mathrm{AMH}$ serum concentrations. One of the earliest studies showed that serum AMH concentrations on cycle day 3 were correlated with the number of oocytes retrieved. However, $\mathrm{AMH}$ and embryo morphology were not correlated after conventional ovarian stimulation in IVF. Moreover, $\mathrm{AMH}$ and the chromosomal competence of embryos were also not correlated. Hence, that study concluded that due to the lack of a consistent correlation with embryo morphology and embryo aneuploidy rates, there is no evidence for a direct relationship between oocyte quantity and embryo quality (41). Similarly, another study showed that although AMH could be used to predict the response in terms of mature oocytes and the number of oocytes that were fertilized, it was neither able to evaluate oocyte quality nor the development of high-quality embryos and resulting conception (42). Another very recent study compared day 2 embryo quality among patients with normal or low OR based on AMH levels. Embryos derived from patients with low ovarian response have similar morphokinetic characteristics and cleavage stage patterns as embryos from patients with normal ovarian response indicating no role for $\mathrm{AMH}$ in predicting embryo quality (43). Finally, there is also no evidence indicating significant differences in rates of congenital anomalies, birth weight or gestational age at delivery between women with normal or poor OR markers. Hence, AMH serum concentrations do not appear to affect pregnancy losses, the incidence of congenital anomalies, birth weight or gestational age at delivery after adjusting for maternal age (44).

A number of studies have been looking at the relationship between AMH levels in women with a compromised OR due to either ovarian diseases such as endometriosis or those who survived after being treated for cancer. The latter group of cancer survivors is thought to be at risk for decreased fertility and premature ovarian insufficiency. However, some of the earliest studies reporting fecundity rates did not detect differences with healthy controls (45). Moreover, the median decline in AMH levels over time in long-term female cancer survivors was not accelerated and similar to that observed in healthy controls (46). Therefore, there is no direct evidence demonstrating that a lower $\mathrm{AMH}$ is predictive of reduced chance to conceive naturally after cancer treatment. A retrospective study reported that there was no difference in pregnancy occurrence with detectable or undetectable post-treatment $\mathrm{AMH}$ in women previously treated for breast cancer (47). Finally, natural pregnancy has been reported even when $\mathrm{AMH}$ was undetectable after cancer treatment. Up to 20 years after cancer treatment attempts to establish a pregnancy were mostly successful. The clinical significance of AMH reflecting the true probability of fertility was also limited in cancer survivors (48). 
Similarly, after ovarian surgery for ovarian benign ovarian cysts postoperative AMH serum levels were not different between pregnant and non-pregnant women. The percentage change in $\mathrm{AMH}$ at 2 years did not differ significantly between the women who conceived versus those who did not. Hence, the postoperative AMH decrease that follows ovarian cyst surgery might not reduce the chances to achieve pregnancy (49). It is difficult to draw any conclusion on the predictive value of low $\mathrm{AMH}$ after ovarian cystectomy on fertility outcome as most studies do not include pregnancy as an outcome. Interpretation of results from studies reporting pregnancy needs to be cautious, as we need to know whether those women included in the studies sought to become pregnant, and the studies usually only report pregnancy as a secondary outcome (50).

In conclusion, $\mathrm{AMH}$ is produced by small pre-antral and antral follicles and is therefore a good marker for the number of the follicles. It is therefore the best indirect marker for the number primordial follicles since the growing cohort is mobilized out of the primordial pool. During the premenopausal years, the number of primordial follicles gradually decreases, whereas during these years the risk for DNA damage gradually increases. The latter probably does not directly affect AMH production by the decreasing cohort of follicles, but it does affect the quality of the remaining cohort. Although these processes seem to go hand in hand during natural aging, they have a different origin. It is therefore that AMH correctly predicts the number of follicles or oocytes after whatever treatment is initiated, but it cannot predict the amount of genetic damage that eventually determines embryo quality and subsequent pregnancy (35). The pros and cons of whether $\mathrm{AMH}$ is the primary marker for fertility are summarized in Table 1.

\section{Declaration of interest}

The authors declare that there is no conflict of interest that could be perceived as prejudicing the impartiality of this article.

\section{Funding}

This research did not receive any specific grant from any funding agency in the public, commercial or not-for-profit sector.

\section{References}

1 Weenen C, Laven JSE, Von Bergh ARM, Cranfield M, Groome NP, Visser JA, Kramer P, Fauser BC \& Themmen AP. Anti-Müllerian hormone expression pattern in the human ovary: potential implications for initial and cyclic follicle recruitment. Molecular
Human Reproduction 200410 77-83. (https://doi.org/10.1093/molehr/ gah015)

2 Jeppesen JV, Anderson RA, Kelsey TW, Christiansen SL, Kristensen SG, Jayaprakasan K, Raine-Fenning N, Campbell BK \& Yding Andersen C. Which follicles make the most anti-Mullerian hormone in humans? Evidence for an abrupt decline in AMH production at the time of follicle selection. Molecular Human Reproduction 201319 519-527. (https://doi.org/10.1093/molehr/gat024)

3 Rajpert-De Meyts E, Jørgensen N, Graem N, Müller J, Cate RL \& Skakkebaek NE. Expression of anti-Müllerian hormone during normal and pathological gonadal development: association with differentiation of Sertoli and granulosa cells. Journal of Clinical Endocrinology and Metabolism 199984 3836-3844. (https://doi. org/10.1210/jcem.84.10.6047)

4 Durlinger ALL, Gruijters MJG, Kramer P, Karels B, Ingraham HA, Nachtigal MW, Uilenbroek JT, Grootegoed JA \& Themmen AP. AntiMüllerian hormone inhibits initiation of primordial follicle growth in the mouse ovary. Endocrinology 2002143 1076-1084. (https://doi. org/10.1210/endo.143.3.8691)

5 Durlinger AL, Kramer P, Karels B, de Jong FH, Uilenbroek JT, Grootegoed JA \& Themmen AP. Control of primordial follicle recruitment by anti-Müllerian hormone in the mouse ovary. Endocrinology 1999140 5789-5796. (https://doi.org/10.1210/ endo.140.12.7204)

6 Durlinger AL, Gruijters MJ, Kramer P, Karels B, Kumar TR, Matzuk MM, Rose UM, de Jong FH, Uilenbroek JT, Grootegoed JA et al. Anti-Müllerian hormone attenuates the effects of FSH on follicle development in the mouse ovary. Endocrinology 2001142 4891-4899. (https://doi.org/10.1210/endo.142.11.8486)

7 McGee EA \& Hsueh AJ. Initial and cyclic recruitment of ovarian follicles. Endocrine Reviews 200021 200-214. (https://doi. org/10.1210/edrv.21.2.0394)

8 Lebbe M \& Woodruff TK. Involvement of androgens in ovarian health and disease. Molecular Human Reproduction 201319 828-837. (https://doi.org/10.1093/molehr/gat065)

9 Grynberg M, Pierre A, Rey R, Leclerc A, Arouche N, Hesters L, CatteauJonard S, Frydman R, Picard JY, Fanchin R et al. Differential regulation of ovarian anti-Müllerian hormone (AMH) by estradiol through $\alpha$ - and $\beta$-estrogen receptors. Journal of Clinical Endocrinology and Metabolism 201297 E1649-E1657. (https://doi.org/10.1210/jc.2011-3133)

10 Dewailly D, Andersen CY, Balen A, Broekmans F, Dilaver N, Fanchin R, Griesinger G, Kelsey TW, La Marca A, Lambalk C et al. The physiology and clinical utility of anti-Mullerian hormone in women. Human Reproduction Update 201420 370-385. (https://doi. org/10.1093/humupd/dmt062)

11 Korsholm AS, Petersen KB, Bentzen JG, Hilsted LM, Andersen AN \& Hvidman HW. Investigation of anti-Müllerian hormone concentrations in relation to natural conception rate and time to pregnancy. Reproductive Biomedicine Online 201836 568-575. (https:// doi.org/10.1016/j.rbmo.2018.01.013)

12 Fanchin R, Schonäuer LM, Righini C, Guibourdenche J, Frydman R \& Taieb J. Serum anti-Müllerian hormone is more strongly related to ovarian follicular status than serum inhibin B, estradiol, FSH and LH on day 3. Human Reproduction 200318 323-327. (https://doi. org/10.1093/humrep/deg042)

13 Van Rooij IA, Broekmans FJM, te Velde ER, Fauser BCJM, Bancsi LFJMM, de Jong FH \& Themmen AP. Serum anti-Müllerian hormone levels: a novel measure of ovarian reserve. Human Reproduction 200217 3065-3071. (https://doi.org/10.1093/ humrep/17.12.3065)

14 Findlay JK, Hutt KJ, Hickey M \& Anderson RA. What is the 'ovarian reserve'? Fertility and Sterility 2015103 628-630. (https://doi. org/10.1016/j.fertnstert.2014.10.037)

15 Franks S. Polycystic ovary syndrome. New England Journal of Medicine 1995333 853-861. (https://doi.org/10.1056/ NEJM199509283331307) 
16 Norman RJ, Dewailly D, Legro RS \& Hickey TE. Polycystic ovary syndrome. Lancet 2007370 685-697. (https://doi.org/10.1016/ S0140-6736(07)61345-2)

17 Pigny P, Merlen E, Robert Y, Cortet-Rudelli C, Decanter C, Jonard S \& Dewailly D. Elevated serum level of anti-Mullerian hormone in patients with polycystic ovary syndrome: relationship to the ovarian follicle excess and to the follicular arrest. Journal of Clinical Endocrinology and Metabolism 200388 5957-5962. (https://doi. org/10.1210/jc.2003-030727)

18 Iliodromiti S, Kelsey TW, Anderson RA \& Nelson SM. Can antiMullerian hormone predict the diagnosis of polycystic ovary syndrome? A systematic review and meta-analysis of extracted data. Journal of Clinical Endocrinology and Metabolism 201398 3332-3340. (https://doi.org/10.1210/jc.2013-1393)

19 Pellatt L, Hanna L, Brincat M, Galea R, Brain H, Whitehead S \& Mason H. Granulosa cell production of anti-Müllerian hormone is increased in polycystic ovaries. Journal of Clinical Endocrinology and Metabolism 200792 240-245. (https://doi.org/10.1210/jc.2006-1582)

20 Alebić MŠ, Stojanović N, Duhamel A \& Dewailly D. The phenotypic diversity in per-follicle anti-Müllerian hormone production in polycystic ovary syndrome. Human Reproduction 201530 1927-1933. (https://doi.org/10.1093/humrep/dev131)

21 Mahran A, Abdelmeged A, El-Adawy AR, Eissa MK, Shaw RW \& Amer SA. The predictive value of circulating anti-Müllerian hormone in women with polycystic ovarian syndrome receiving clomiphene citrate: a prospective observational study. Journal of Clinical Endocrinology and Metabolism 201398 4170-4175. (https://doi. org/10.1210/jc.2013-2193)

22 Köninger A, Sauter L, Edimiris P, Kasimir-Bauer S, Kimmig R, Strowitzki T \& Schmidt B. Predictive markers for the FSH sensitivity of women with polycystic ovarian syndrome. Human Reproduction 201429 518-524. (https://doi.org/10.1093/humrep/det468)

23 Amer SA, Mahran A, Abdelmaged A, El-Adawy AR, Eissa MK \& Shaw RW. The influence of circulating anti-Müllerian hormone on ovarian responsiveness to ovulation induction with gonadotrophins in women with polycystic ovarian syndrome: a pilot study. Reproductive Biology and Endocrinology 201311 115. (https://doi. org/10.1186/1477-7827-11-115)

24 Kim JY, Yi G, Kim YR, Chung JY, Ahn JH, Uhm YK, Jee BC, Suh CS \& Kim SH. Association between serum anti-Müllerian hormone level and ovarian response to mild stimulation in normoovulatory women and anovulatory women with polycystic ovary syndrome. Clinical and Experimental Reproductive Medicine 201340 95-99. (https://doi. org/10.5653/cerm.2013.40.2.95)

25 Lie Fong S, Schipper I, de Jong FH, Themmen APN, Visser JA \& Laven JSE. Serum anti-Müllerian hormone and inhibin B concentrations are not useful predictors of ovarian response during ovulation induction treatment with recombinant folliclestimulating hormone in women with polycystic ovary syndrome. Fertility and Sterility 201196 459-463. (https://doi.org/10.1016/j. fertnstert.2011.05.084)

26 Amer SA, Li TC \& Ledger WL. The value of measuring anti-Mullerian hormone in women with anovulatory polycystic ovary syndrome undergoing laparoscopic ovarian diathermy. Human Reproduction 200924 2760-2766. (https://doi.org/10.1093/humrep/dep271)

27 Abu Hashim H. Predictors of success of laparoscopic ovarian drilling in women with polycystic ovary syndrome: an evidence-based approach. Archives of Gynecology and Obstetrics 2015291 11-18. (https://doi.org/10.1007/s00404-014-3447-6)

28 Sunj M, Canic T, Jeroncic A, Karelovic D, Tandara M, Juric S \& Palada I. Anti-Müllerian hormone, testosterone and free androgen index following the dose-adjusted unilateral diathermy in women with polycystic ovary syndrome. European Journal of Obstetrics, Gynecology, and Reproductive Biology 2014179 163-169. (https://doi. org/10.1016/j.ejogrb.2014.05.011)
29 Baker VL. Primary ovarian insufficiency in the adolescent. Current Opinion in Obstetrics and Gynecology 201325 375-381. (https://doi. org/10.1097/GCO.0b013e328364ed2a)

30 Broer SL, Mol B, Dólleman M, Fauser BC \& Broekmans FJM. The role of anti-Müllerian hormone assessment in assisted reproductive technology outcome. Current Opinion in Obstetrics and Gynecology 201022 193-201. (https://doi.org/10.1097/GCO.0b013e3283384911)

31 Gleicher N, Weghofer A \& Barad DH. Anti-Müllerian hormone (AMH) defines, independent of age, low versus good live-birth chances in women with severely diminished ovarian reserve. Fertility and Sterility 201094 2824-2827. (https://doi.org/10.1016/j. fertnstert.2010.04.067)

32 Bertone-Johnson ER, Manson JE, Purdue-Smithe AC, Steiner AZ, Eliassen AH, Hankinson SE, Rosner BA \& Whitcomb BW. AntiMüllerian hormone levels and incidence of early natural menopause in a prospective study. Human Reproduction 201833 1175-1182. (https://doi.org/10.1093/humrep/dey077)

33 Decanter C, Peigne M, Mailliez A, Morschhauser F, Dassonneville A, Dewailly D \& Pigny P. Toward a better follow-up of ovarian recovery in young women after chemotherapy with a hypersensitive antiMullerian hormone assay. Fertility and Sterility 2014102 483-487. (https://doi.org/10.1016/j.fertnstert.2014.05.014)

34 Broekmans FJ, Visser JA, Laven JS, Broer SL, Themmen AP \& Fauser BC. Anti-Müllerian hormone and ovarian dysfunction. Trends in Endocrinology and Metabolism 200819 340-347. (https://doi. org/10.1016/j.tem.2008.08.002)

35 Laven JSE, Visser JA, Uitterlinden AG, Vermeij WP \& Hoeijmakers JHJ. Menopause: genome stability as new paradigm. Maturitas 201692 15-23. (https://doi.org/10.1016/j. maturitas.2016.07.006)

36 Zarek SM, Mitchell EM, Sjaarda LA, Mumford SL, Silver RM, Stanford JB, Galai N, White MV, Schliep KC, DeCherney AH et al. Is anti-Müllerian hormone associated with fecundability? Findings from the EAGeR trial. Journal of Clinical Endocrinology and Metabolism 2015100 4215-4221. (https://doi.org/10.1210/jc.2015-2474)

37 Hagen CP, Vestergaard S, Juul A, Skakkebæk NE, Andersson AM, Main KM, Hjøllund NH, Ernst E, Bonde JP, Anderson RA et al. Low concentration of circulating antiMüllerian hormone is not predictive of reduced fecundability in young healthy women: a prospective cohort study. Fertility and Sterility 201298 1602.e2-1608.e2. (https:// doi.org/10.1016/j.fertnstert.2012.08.008)

38 Steiner AZ, Pritchard D, Stanczyk FZ, Kesner JS, Meadows JW, Herring AH \& Baird DD. Association between biomarkers of ovarian reserve and infertility among older women of reproductive age. JAMA 2017318 1367-1376. (https://doi.org/10.1001/jama.2017.14588)

39 Iliodromiti S, Kelsey TW, Wu O, Anderson RA \& Nelson SM. The predictive accuracy of anti-Müllerian hormone for live birth after assisted conception: a systematic review and meta-analysis of the literature. Human Reproduction Update 201420 560-570. (https://doi. org/10.1093/humupd/dmu003)

40 Gleicher N, Kushnir VA, Sen A, Darmon SK, Weghofer A, Wu YG, Wang Q, Zhang L, Albertini DF \& Barad DH. Definition by FSH, AMH and embryo numbers of good-, intermediate- and poor-prognosis patients suggests previously unknown IVF outcome-determining factor associated with AMH. Journal of Translational Medicine 201614 172. (https://doi.org/10.1186/s12967-016-0924-7)

41 Lie Fong S, Baart EB, Martini E, Schipper I, Visser JA, Themmen AP, de Jong FH, Fauser BJ \& Laven JS. Anti-Müllerian hormone: a marker for oocyte quantity, oocyte quality and embryo quality? Reproductive Biomedicine Online 200816 664-670. (https://doi.org/10.1016/S14726483(10)60480-4)

42 Aydın GA, Yavuz A, Terzi H \& Kutlu T. Assessment of the relationship of basal serum anti-Mullerian hormone levels with oocyte quality and pregnancy outcomes in patients undergoing ICSI. Iranian Journal of Reproductive Medicine 201513 231-236. 
43 Alexopoulou E, Pinborg A, Budtz-Jørgensen E \& Zedeler A. Comparing early embryo morphokinetics with time-lapse microscopy in patients with low and normal ovarian response to ovarian stimulation. Reproductive Biology 201919 127-132. (https:// doi.org/10.1016/j.repbio.2019.03.002)

44 Richardson A, Mascarenhas M \& Balen A. Is a woman's chronological age or 'ovarian age' more important in determining perinatal outcome after assisted reproductive treatment? Human Fertility 2019 Epub. (https://doi.org/10.1080/14647273.2019.1597987)

45 Lie Fong S, Laven JS, Hakvoort-Cammel FG, Schipper I, Visser JA, Themmen AP, de Jong FH \& van den Heuvel-Eibrink MM. Assessment of ovarian reserve in adult childhood cancer survivors using antiMüllerian hormone. Human Reproduction 200924 982-990. (https:// doi.org/10.1093/humrep/den487)

46 van der Kooi AL, van den Heuvel-Eibrink MM, van Noortwijk A, Neggers SJ, Pluijm SM, van Dulmen-den Broeder E, van Dorp W \& Laven JS. Longitudinal follow-up in female Childhood Cancer Survivors: no signs of accelerated ovarian function loss. Human Reproduction 2017 32 193-200. (https://doi.org/10.1093/humrep/dew278)
47 Hamy AS, Porcher R, Eskenazi S, Cuvier C, Giacchetti S, Coussy F, Hocini H, Tournant B, Perret F, Bonfils S et al. Anti-Müllerian hormone in breast cancer patients treated with chemotherapy: a retrospective evaluation of subsequent pregnancies. Reproductive Biomedicine Online 201632 299-307. (https://doi.org/10.1016/j. rbmo.2015.12.008)

48 Hamre H, Kiserud CE, Ruud E, Thorsby PM \& Fosså SD. Gonadal function and parenthood 20 years after treatment for childhood lymphoma: a cross-sectional study. Pediatric Blood and Cancer 2012 59 271-277. (https://doi.org/10.1002/pbc.23363)

49 Lind T, Lampic C, Olofsson JI \& Rodriguez-Wallberg KA. Postoperative AMH reduction is not associated with reduced fecundity two years following ovarian cyst surgery. Gynecological Endocrinology 201632 745-748. (https://doi.org/10.3109/09513590.2 016.1166198)

50 Wong QHY \& Anderson RA. The role of antiMullerian hormone in assessing ovarian damage from chemotherapy, radiotherapy and surgery. Current Opinion in Endocrinology, Diabetes, and Obesity 2018 25 391-398. (https://doi.org/10.1097/MED.0000000000000447)

Received 20 May 2019

Revised version received 6 August 2019

Accepted 9 August 2019 